\title{
Peri-operative chemotherapy for resectable colorectal lung metastasis: a systematic review and meta-analysis
}

\author{
Yuting $\mathrm{Li}^{1} \cdot$ You Qin ${ }^{1}$ (D)
}

Received: 11 January 2020 / Accepted: 30 January 2020 / Published online: 8 February 2020

(c) The Author(s) 2020

\begin{abstract}
Purpose Several studies have evaluated surgical resection of pulmonary metastases as a standard treatment option for colorectal cancer (CRC) patients with resectable pulmonary metastases. However, the role of peri-operative chemotherapy after complete resection of pulmonary metastases from CRC patients is still controversial. This systematic review and meta-analysis is aimed to investigate the clinical efficacy of peri-operative chemotherapy after resection of CRC pulmonary metastases. Methods PubMed, the Cochrane Library databases, and Embase were searched for studies evaluating the effect of perioperative chemotherapy on the survival of patients with CRC after pulmonary metastasectomy. The hazard ratio (HR) was used for analyzing overall survival (OS) and progression-free survival (PFS)/recurrence-free survival (RFS)/disease-free survival (DFS).

Results Eight studies were included in the final analysis. The outcome showed that peri-operative chemotherapy had a significant favourable effect on OS (HR 0.83, 95\% CI 0.75-0.92, $p<0.05$ ) and PFS/RFS/DFS (HR 0.67, 95\% CI 0.53-0.86, $p<0.05)$ in patients who received pulmonary metastasectomy. Multivariate analysis also validated this result (OS: HR $0.56,95 \%$ CI $0.36-0.86, p<0.05$; PFS/RFS/DFS: HR 0.64, 95\% CI 0.46-0.87, $p<0.05$ ). There was a significant benefit in peri-operative group on OS and PFS/RFS/DFS in studies with R0 resection of pulmonary metastases (OS: HR 0.72, 95\% CI 0.53-0.97, $p<0.05$; PFS/RFS/DFS: HR 0.72, 95\% CI 0.54-0.95, $p<0.05$ ) and metachronous pulmonary metastases (OS: HR 0.40, 95\% CI 0.22-0.75, $p<0.05$; PFS/RFS/DFS: HR 0.67, 95\% CI 0.49-0.92, $p<0.05$ ).

Conclusion Our meta-analysis demonstrated a significant difference in favor of peri-operative chemotherapy in CRC patients who underwent resection of pulmonary metastases. More clinical data and studies are needed to validate the findings of our study.
\end{abstract}

Keywords Colorectal cancer $\cdot$ Pulmonary metastases $\cdot$ Chemotherapy $\cdot$ Meta-analysis

\section{Abbreviations}

CRC Colorectal cancer

HR Hazard ratio

OS Overall survival

PFS Progression-free survival

RFS Recurrence-free survival

Electronic supplementary material The online version of this article (https://doi.org/10.1007/s00432-020-03142-9) contains supplementary material, which is available to authorized users.

You Qin

qinyou@ hust.edu.cn

Yuting Li

lytwhxh@163.com

1 Cancer Center, Union Hospital, Tongji Medical College, Huazhong University of Science and Technology, Wuhan 430022, People's Republic of China
DFS Disease-free survival

CEA Carcinoembryonic antigen

DFI Disease-free interval

NOS Newcastle-Ottawa Scale

FOLFOX Intravenous 5-FU plus oxaliplatin

FOLFIRI Intravenous 5-FU plus irinotecan

\section{Background}

CRC is the third most common cancer in the world. It was estimated that more than one million cases and 600 thousands deaths occurred in 2012 (Torre et al. 2015). The lung is known to be the second most frequent site of metastases. 19\% of CRC patients were found to have synchronous metastases (present at the time of CRC diagnosis) before treatment, $11 \%$ of whom had lung metastases (Mitry et al. 
2010). About $2-7 \%$ of patients have isolated metastases, while about $10 \%$ of patients will have synchronous pulmonary and liver metastases (Johnston et al. 2012).

Despite the lack of randomized studies, pulmonary metastasection has been recognized as a standard treatment for CRC patients with resectable pulmonary metastases. A pooled analysis of CRC pulmonary oligometastasis found that 5-year survival rate after pulmonary metastasectomy was $54.3 \%$ (Salah et al. 2012). In accordance with this finding, a series of studies demonstrated an overall 5-year survival rate of approximately $30.5-54.4 \%$ after resection of pulmonary metastases (Goya et al. 1989; McAfee et al. 1992; McCormack et al. 1992; Zampino et al. 2014; Salah et al. 2015). The prognostic factors of these patients included the number of pulmonary metastases, serum carcinoembryonic antigen (CEA), mediastinal and hilar lymph node involvement, and the disease-free interval (DFI) between the resection of the primary tumor and pulmonary metastases (Pfannschmidt et al. 2007).

Although surgical resection significantly improves the survival of these patients, relapses are still a challenge for treatment. It has been reported that the rate of relapse after resection of colorectal metastases ranges from 20 to $68 \%$ (Welter et al. 2007; Pfannschmidt et al. 2010; Guerrera et al. 2016). Therefore, it is still an urgent problem to find effective therapeutic strategies to reduce the risk of relapse in these patients (Brandi et al. 2016). However, the role of systemic chemotherapy in these patients is still inconsistent. Only a few studies have reported that peri-operative chemotherapy contributes to survival after resection of CRC pulmonary metastases(Muñoz Llarena et al. 2007; Kaira et al. 2011), while other studies have showed that these patients can't benefit from systemic chemotherapy (Brandi et al. 2013; Park et al. 2017). A literature review of studies that examined whether peri-operative chemotherapy provided benefit for CRC patients with resection of lung metastases identified six retrospective studies (Guerrera et al. 2017). Five of these studies showed that adjuvant chemotherapy did not benefit OS, while a single study showed that chemotherapy positively impacted OS. However, meta-analysis was not conducted in this review. Therefore, we performed a systematic review and meta-analysis to evaluate the effectiveness of peri-operative chemotherapy in the treatment of CRC patients receiving resection of pulmonary metastases.

\section{Method}

\section{Search strategy}

Studies were identified by searching PubMed, Cochrane Library databases, and Embase without language restriction. The systematic review was undertaken on January 21, 2018.
The following terms and keywords were used: pulmonary metastasis, pulmonary metastases, lung metastases, lung metastasis, colorectal cancer, colorectal neoplasms, colorectal tumor, colorectal carcinoma, rectal cancer, colon cancer, adjuvant chemotherapy, post-operative chemotherapy, neoadjuvant chemotherapy, and peri-operative chemotherapy. Relevant articles and abstracts were reviewed and selected based on the defined inclusion and exclusion criteria.

\section{Inclusion criteria}

Articles were included if they were published reports that included patients treated with or without peri-operative chemotherapy with resectable colorectal lung metastases. Only studies that reported patient survival data were included. Patients with synchronous or metachronous lung metastasis (develop during treatment or follow-up) were included.

\section{Exclusion criteria}

Studies that did not examine long-term follow-up were excluded.

\section{Validity assessment}

The quality of the selected studies was evaluated using the Newcastle-Ottawa Scale (NOS).

\section{Data extraction}

The studies were independently examined by two investigators. First author, year of publication, study type, study population characteristics, number of subjects, length of follow-up, and outcomes were recorded. Publication bias was investigated by funnel plots.

\section{Statistical analysis}

Stata software was used to evaluate the overall effect of peri-operative chemotherapy on survival. The results were obtained as the hazard ratio of PFS/RFS/DFS and OS. $\mathrm{I}^{2}$ was used to evaluate heterogeneity across studies. A $p$ value of $<0.05$ was considered statistically significant.

\section{Results}

To date, there have been no reports of randomized trials that compared surgery to neo-adjuvant or adjuvant chemotherapy combined with surgery.

Figure 1 shows the summary profile of the search. We identified 11 potential cohort studies that examined 
Fig. 1 Flow chart of trial selection

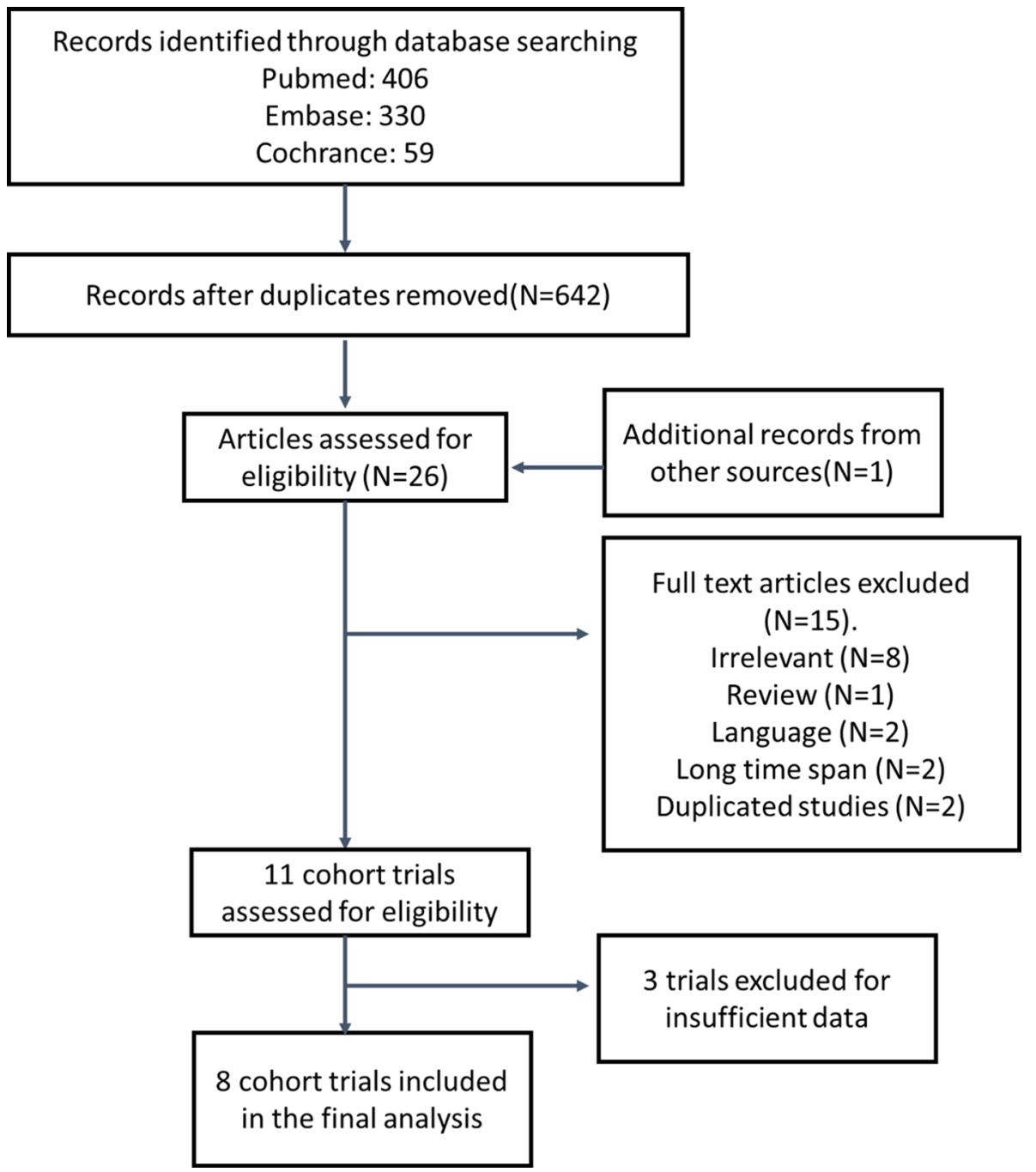

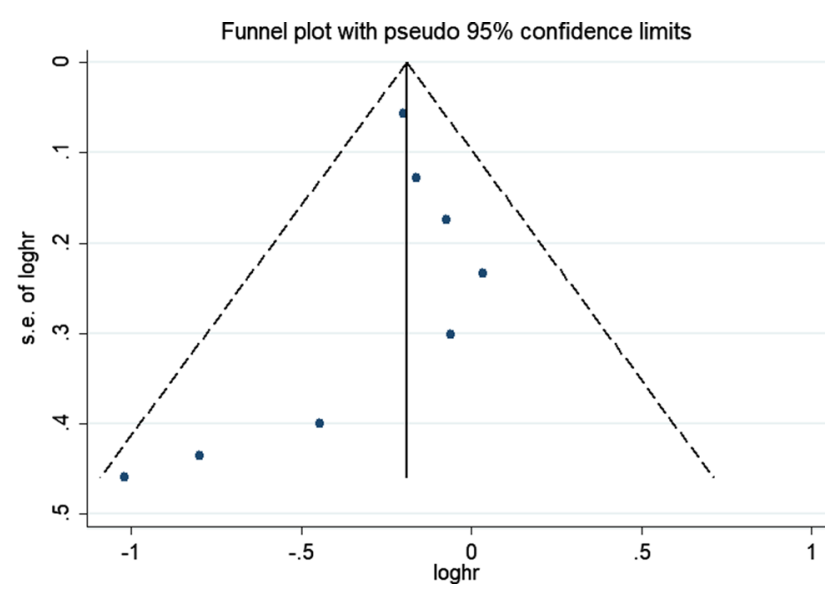

Fig. 2 Funnel plot of the included studies

peri-operative chemotherapy in combination with surgery for the treatment of resectable lung metastasis. Of the 11 studies, three studies were excluded because of insufficient data. Eight studies were eligible for the meta-analysis. Potential publication biases were evaluated using the funnel plot, which showed no publication bias (Fig. 2).

A total of 1936 patients in eight studies were evaluated in this meta-analysis, of whom 926 patients received surgery alone and 1010 patients received peri-operative chemotherapy and surgery (Guerrera et al. 2016, Park et al. 2016, Karim et al. 2017, Park et al. 2017, Shiomi et al. 2017, Hawkes et al. 2012, Kaira et al. 2011, Okumura et al. 2017). Characteristics of the included studies are summarized in Table 1. These studies were all published between 2011 and 2017. Three studies were conducted in Japan, two in Korea, one in Italy, one in Canada, and one in the United Kingdom. The sample size ranged from 51 to 785 . Most studies evaluated the role of peri-operative chemotherapy after R0 (no residual disease) resection. Most patients received adjuvant chemotherapy, while others received neo-adjuvant chemotherapy or both. Chemotherapy regimens included oxaliplatin-based chemotherapy, irinotecan-based therapy, molecular targeted drugs, and 5-FU monotherapy. Chemotherapy 


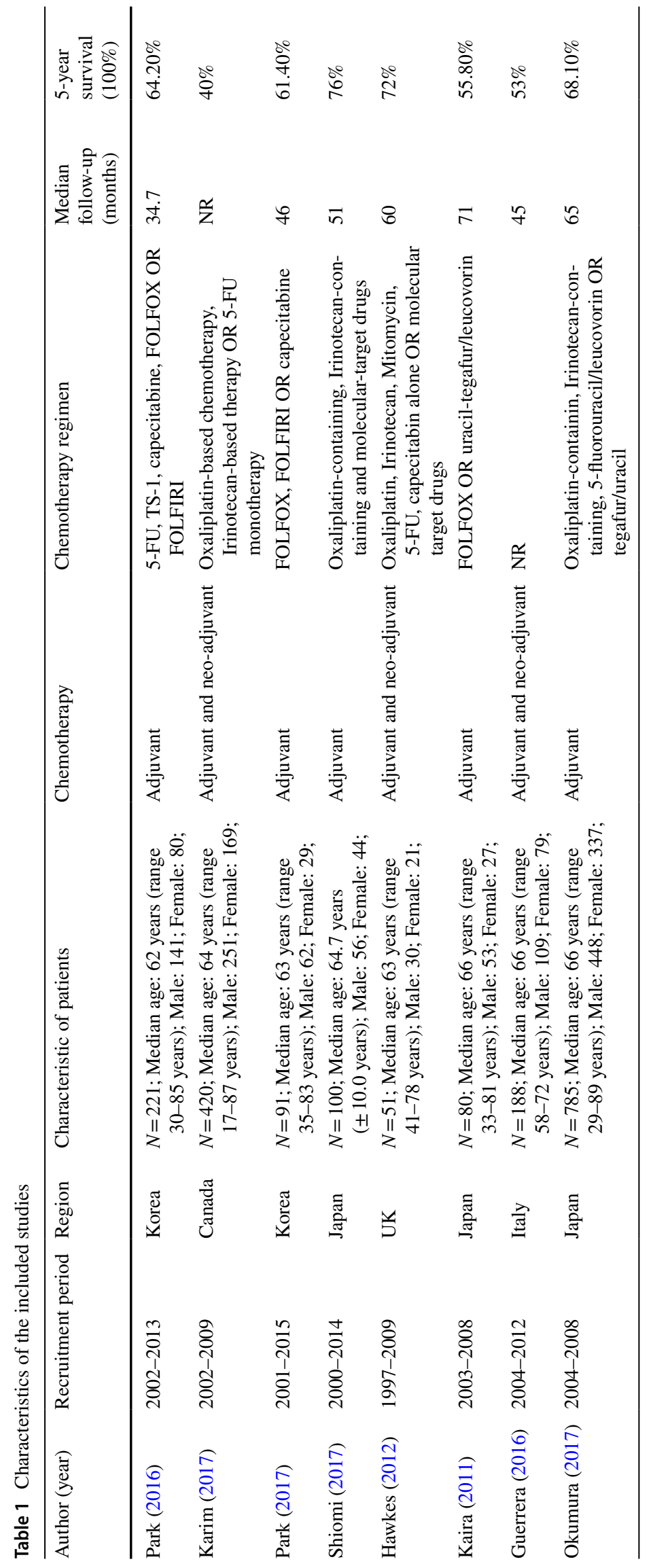


regimen was not described in one study (Guerrera et al. 2016). All studies were retrospective analyses. The quality assessment of the included studies was evaluated by NOS. The scores ranged from 7 to 9 . The characteristics of the included studies contained sex and age (Table S1).

All eight studies that investigated OS were included for meta-analysis. The heterogeneity of the therapeutic effect was not significant $\left(p=0.404, I^{2}=3.3 \%\right.$ ). The outcome of the random effect model of the meta-analysis revealed that treatment with peri-operative chemotherapy significantly prolonged OS in comparison to treatment with only pulmonary metastasectomy (HR $0.83,95 \%$ CI $0.75-0.92, p<0.05$ ) (Fig. 3). PFS/RFS/DFS was described in four studies. In these four studies, chemotherapy was performed in the postsurgical setting. The meta-analysis results suggested that peri-operative chemotherapy reduced the risk of progression or recurrence (HR 0.67, 95\% CI 0.53-0.86, $p<0.05$ ) (Fig. 4). No heterogeneity was identified ( $p=0.733$, $\left.I^{2}=0.0 \%\right)$. Independent prognostic factors were verified using multivariate analyses in four studies. Peri-operative chemotherapy strongly affected PFS/RFS/DFS and OS by multivariate analysis compared to surgery alone (OS: HR $0.56,95 \%$ CI $0.36-0.86, p<0.05$; PFS/RFS/DFS: HR $0.64,95 \%$ CI $0.46-0.87, p<0.05$ ) (Tables 2, 3). Different predictors were included in each final multivariate model, whereas all four studies adjusted for age, CEA level, tumor
Fig. 3 HR analysis of OS for peri-operative chemotherapy vs. surgery alone

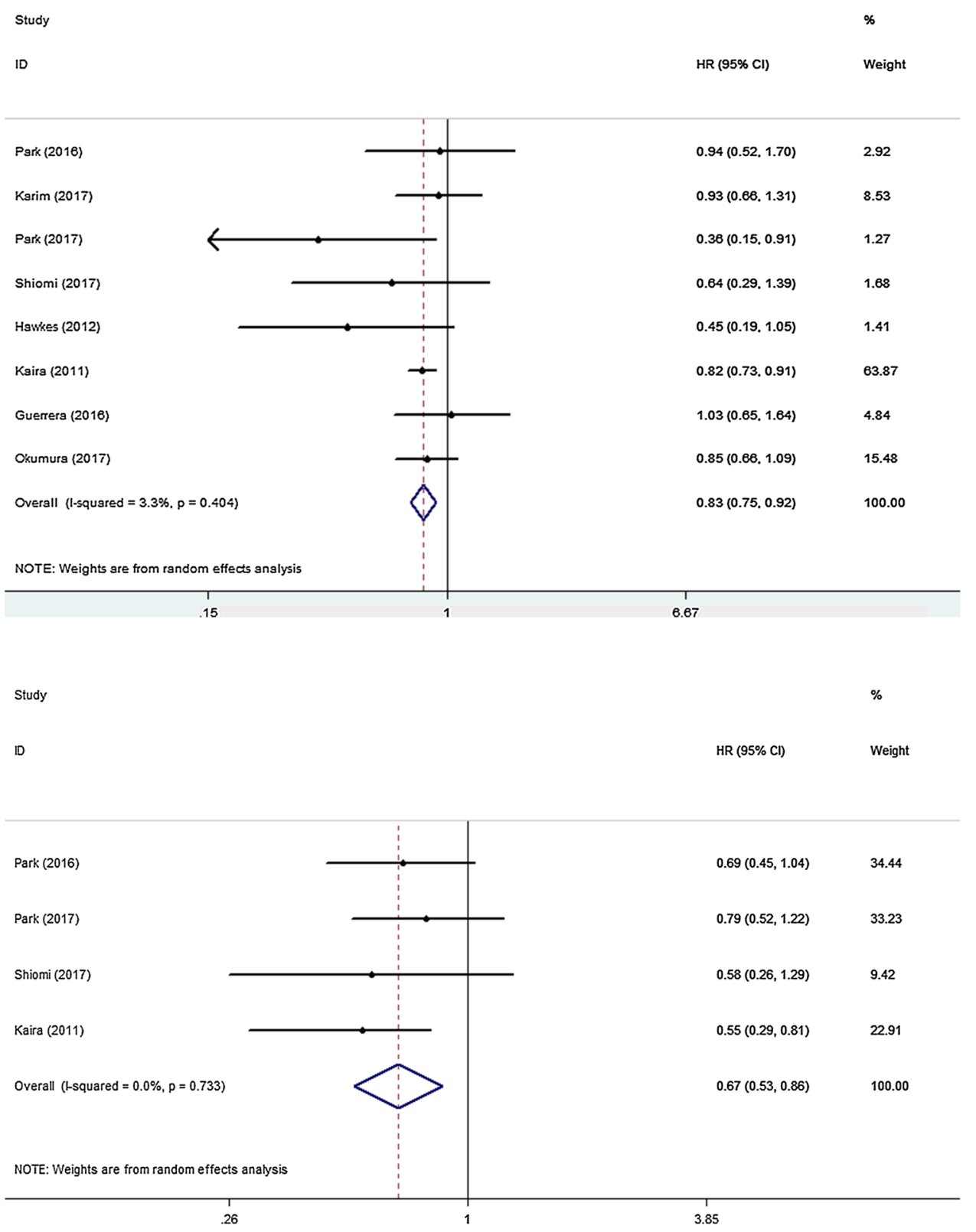

Fig. 4 HR analysis of PFS/RFS/ DFS for peri-operative chemotherapy vs. surgery alone 
Table 2 Subgroup analyses of HR of OS for peri-operative chemotherapy vs. surgery alone
Table 3 Subgroup analyses of HR of PFS/RFS/DFS for peri-operative chemotherapy vs. surgery alone

\begin{tabular}{lcccr}
\hline Study of subgroup & $\begin{array}{l}\text { Chemotherapy and } \\
\text { surgery }\end{array}$ & Surgery alone & HR $(95 \%$ CI $)$ & Weight \\
\hline Multivariate analysis & & & & \\
Park (2017) & 63 & 28 & $0.47(0.11,2.01)$ & 8.88 \\
Shiomi (2017) & 42 & 58 & $0.35(0.14,0.81)$ & 24.49 \\
Guerrera (2016) & 122 & 66 & $0.67(0.40,1.15)$ & 66.62 \\
Subtotal & 227 & 152 & $0.56(0.36,0.86)$ & \\
Heterogeneity: $I$-squared $=0.0 \%, p=0.444$ & & & \\
R0 resection & & & & \\
Park (2016) & 176 & 45 & $0.94(0.52,1.70)$ & 19.23 \\
Park (2017) & 63 & 28 & $0.64(0.29,1.39)$ & 12.44 \\
Shiomi (2017) & 42 & 58 & $0.45(0.19,1.05)$ & 10.76 \\
Hawkes (2012) & 38 & 409 & $0.85(0.66,1.09)$ & 47.74 \\
Okumura (2017) & 376 & 553 & $0.72(0.53,0.97)$ & \\
Subtotal & 695 & & & \\
Heterogeneity: $I$-squared $=0.0 \%, p=0.425$ & & & \\
Metachronous pulmonary metastases & 63 & 28 & $0.36(0.15,0.91)$ & 47.35 \\
Park (2017) & 38 & 13 & $0.40(0.22,0.75)$ & 52.65 \\
Hawkes (2012) & 101 & 41 & & \\
Subtotal & & & & \\
Heterogeneity: $I$-squared $=0.0 \%, p=0.725$ & & & \\
\hline & & & & \\
\hline
\end{tabular}

\begin{tabular}{lcccc}
\hline Study of subgroup & $\begin{array}{l}\text { Chemotherapy and } \\
\text { surgery }\end{array}$ & Surgery alone & HR $(95 \%$ CI $)$ & Weight \\
\hline Multivariate analysis & & & & \\
$\quad$ Park (2016) & 176 & 45 & $0.65(0.42,1.00)$ & 53.95 \\
Park (2017) & 63 & 28 & $0.92(0.43,1.98)$ & 17.16 \\
Shiomi (2017) & 42 & 58 & $0.49(0.27,0.88)$ & 28.89 \\
Subtotal & 281 & 131 & $0.64(0.46,0.87)$ & \\
Heterogeneity: $I$-squared $=0.0 \%, p=0.438$ & & & \\
R0 resection & & & & \\
Park (2016) & 176 & 45 & $1.79(0.52,1.22)$ & 43.11 \\
Park (2017) & 63 & 28 & $0.58(0.26,1.29)$ & 12.22 \\
Shiomi (2017) & 42 & 131 & $0.72(0.54,0.95)$ & \\
Subtotal & 281 & & & \\
Heterogeneity: $I$-squared $=0.0 \%, p=0.779)$ & & & \\
Metachronous pulmonary metastases & 151 & 41 & $0.57(0.38,0.87)$ & 51.26 \\
Park (2016) & 63 & 28 & $0.79(0.52,1.22)$ & 48.74 \\
Park (2017) & 214 & 69 & $0.67(0.49,0.92)$ & \\
Subtotal & & &
\end{tabular}

location, and peri-operative chemotherapy in the multivariate analysis.

The efficacy of peri-operative chemotherapy after pulmonary metastasectomy was further investigated in CRC patients after R0 resection. Five studies were included in the final analysis. Hawkes et al., and Okumura et al., did not report PFS/RFS/DFS data. There was a significant different benefit in the peri-operative group for OS and PFS/RFS/DFS (OS: HR 0.82, 95\% CI 0.74-0.90, $p<0.05$; PFS/RFS/DFS: HR $0.72,95 \%$ CI $0.54-0.95, p<0.05$ ) (Tables 2,3). Three of these studies assessed OS and PFS of CRC patients with metachronous lung metastases. 
Hawkes et al. provided data on OS, while Park et al. supplied data on PFS/RFS/DFS. A significant improvement was confirmed in OS and PFS/RFS/DFS (OS: HR 0.40, 95\% CI 0.22-0.75, $p<0.05$; PFS/RFS/DFS: HR 0.67, 95\% CI $0.49-0.92, p<0.05)$ (Tables 2, 3).

\section{Discussion}

The need for peri-operative chemotherapy after pulmonary metastasectomy from CRC patients is still a matter of debate due to the lack of evidence. In this study, we evaluated eight retrospective studies concerning the efficacy of chemotherapy in these patients. The HR estimates suggested that patients benefit from peri-operative chemotherapy after resection of pulmonary metastases. For PFS/RFS/DFS, the peri-operative treatment group also improved survival. Multivariate meta-analyses were conducted to adjust for other variables that could have influenced survival, such as age, disease stage, CEA level, and tumor location. Our analyses demonstrated that perioperative chemotherapy was an independent and favorable prognostic factor for OS and PFS/RFS/DFS, which is consistent with previous findings (Muñoz Llarena et al. 2007; Guerrera et al. 2017).

Surgery has become the standard treatment for CRC patients after resection of pulmonary metastases (Goya et al. 1989; Mitry et al. 2010; Zampino et al. 2014; Van Cutsem et al. 2016). Despite the recommendation of adjuvant chemotherapy after surgery for CRC patients with liver metastases (Nordlinger et al. 2008, Van Cutsem et al. 2016), this is not the case for CRC patients with lung metastases (Brandi et al. 2016; Guerrera et al. 2017). "Watch and wait" is regarded to be an appropriate approach after pulmonary metastasectomy in CRC patients for lung involvement, as it may be associated with a better outcome. The different therapeutic recommendation may be due to molecular differences depending on the sites of metastases (Khattak et al. 2012; Yaeger et al. 2014). However, our results showed that peri-operative chemotherapy led to a significant OS and PFS/RFS/DFS benefit in CRC patients in comparison to surgery alone. We further analyzed studies that investigated $\mathrm{R} 0$ resection of pulmonary metastases or metachronous pulmonary metastases. Survival benefits in terms of OS and PFS were also achieved by peri-operative chemotherapy. The benefit of peri-operative chemotherapy may be influenced by the type of chemotherapy regimen received by CRC patients (Nakajima et al. 2017).

There were some limitations to this study. All included studies were retrospective analyses and were associated with a low level of evidence. Compared with randomized control trials, retrospective and non-randomized studies can introduce bias into data analysis and confound the results. For example, adjuvant chemotherapy was likely proposed to a selected subgroup of patients who were fit and without serious complications after surgery, had poor prognosis, or had heavier disease burden. It is also necessary to consider the heterogeneous chemotherapy regimens used in the study. Chemotherapy regimens used in the study included intravenous 5-FU, TS-1, capecitabine, intravenous 5-FU plus oxaliplatin (FOLFOX), intravenous 5-FU plus irinotecan (FOLFIRI), and molecular targeted agents. Recently, these new chemotherapeutic regimens have significantly improved the prognosis of patients with CRC (de Gramont et al. 2000; Saltz et al. 2001; Goldberg et al. 2004). The survival rates of patients treated with chemotherapy after resection of CRC pulmonary metastases have increased over time. This has contributed to the wide range in the efficacy of peri-operative chemotherapy in CRC patients who underwent pulmonary metastectomy. However, it is still difficult to define the chemotherapy regimens, doses, and the number of cycles of peri-operative therapy in practice.

\section{Conclusion}

In conclusion, our study is the first meta-analysis to assess whether peri-operative chemotherapy impacts the survival of CRC patients with resectable pulmonary metastases. Although a significant survival benefit has been observed in these patients, the conclusion is still limited by the fact that the analysis was based on retrospective studies. Randomized control studies focused on peri-operative treatment for this subgroup of patients is warranted.

Authors' contributions YQ and YL contributed to conception and design, acquisition of data, analysis, and interpretation of data. All authors read and approved the final manuscript.

Funding Study design, data collection and analysis, decision to publish, and preparation of the manuscript were supported by National Scientific Foundation of China (Grant No. 81202962).

\section{Compliance with ethical standards}

Conflict of interest The authors declare that they have no competing interests.

Open Access This article is licensed under a Creative Commons Attribution 4.0 International License, which permits use, sharing, adaptation, distribution and reproduction in any medium or format, as long as you give appropriate credit to the original author(s) and the source, provide a link to the Creative Commons licence, and indicate if changes were made. The images or other third party material in this article are included in the article's Creative Commons licence, unless indicated otherwise in a credit line to the material. If material is not included in 
the article's Creative Commons licence and your intended use is not permitted by statutory regulation or exceeds the permitted use, you will need to obtain permission directly from the copyright holder. To view a copy of this licence, visit http://creativecommons.org/licenses/by/4.0/.

\section{References}

Brandi G, Derenzini E, Falcone A, Masi G, Loupakis F, Pietrabissa A, Pinna AD, Ercolani G, Pantaleo MA, Di Girolamo S, Grazi GL, de Rosa F, Biasco G (2013) Adjuvant systemic chemotherapy after putative curative resection of colorectal liver and lung metastases. Clin Colorectal Cancer 12:188-194

Brandi G, De Lorenzo S, Nannini M, Curti S, Ottone M, Dall'Olio FG, Barbera MA, Pantaleo MA, Biasco G (2016) Adjuvant chemotherapy for resected colorectal cancer metastases: literature review and meta-analysis. World J Gastroenterol 22:519-533

de Gramont A, Figer A, Seymour M, Homerin M, Hmissi A, Cassidy J, Boni C, Cortes-Funes H, Cervantes A, Freyer G, Papamichael D, Le Bail N, Louvet C, Hendler D, de Braud F, Wilson C, Morvan F, Bonetti A (2000) Leucovorin and fluorouracil with or without oxaliplatin as first-line treatment in advanced colorectal cancer. J Clin Oncol 18:2938-2947

Goldberg RM, Sargent DJ, Morton RF, Fuchs CS, Ramanathan RK, Williamson SK, Findlay BP, Pitot HC, Alberts SR (2004) A randomized controlled trial of fluorouracil plus leucovorin, irinotecan, and oxaliplatin combinations in patients with previously untreated metastatic colorectal cancer. J Clin Oncol 22:23-30

Goya T, Miyazawa N, Kondo H, Tsuchiya R, Naruke T, Suemasu K (1989) Surgical resection of pulmonary metastases from colorectal cancer. 10-year follow-up. Cancer 64:1418-1421

Guerrera F, Mossetti C, Ceccarelli M, Bruna MC, Bora G, Olivetti S, Lausi PO, Solidoro P, Ciccone G, Ruffini E, Oliaro A, Filosso PL (2016) Surgery of colorectal cancer lung metastases: analysis of survival, recurrence and re-surgery. J Thorac Dis 8:1764-1771

Guerrera F, Falcoz PE, Renaud S, Massard G (2017) Does perioperative chemotherapy improve survival in patients with resectable lung metastases of colorectal cancer? Interact Cardiovasc Thorac Surg 24:789-791

Hawkes EA, Ladas G, Cunningham D, Nicholson AG, Wassilew K, Barbachano Y, Ratnayake G, Rao S, Chau I (2012) Peri-operative chemotherapy in the management of resectable colorectal cancer pulmonary metastases. BMC Cancer 12:326

Johnston FM, Kneuertz PJ, Pawlik TM (2012) Resection of non-hepatic colorectal cancer metastasis. J Gastrointest Oncol 3:59-68

Kaira K, Okumura T, Ohde Y, Takahashi T, Murakami H, Kondo H, Nakajima T, Yamamoto N (2011) Prognostic significance of thymidylate synthase expression in the adjuvant chemotherapy after resection for pulmonary metastases from colorectal cancer. Anticancer Res 31:2763-2771

Karim S, Nanji S, Brennan K, Pramesh CS, Booth CM (2017) Chemotherapy for resected colorectal cancer pulmonary metastases: utilization and outcomes in routine clinical practice. Eur J Surg Oncol 43:1481-1487

Khattak MA, Martin HL, Beeke C, Price T, Carruthers S, Kim S, Padbury R, Karapetis CS (2012) Survival differences in patients with metastatic colorectal cancer and with single site metastatic disease at initial presentation: results from South Australian clinical registry for advanced colorectal cancer. Clin Colorectal Cancer $11: 247-254$

McAfee MK, Allen MS, Trastek VF, Ilstrup DM, Deschamps C, Pairolero PC (1992) Colorectal lung metastases: results of surgical excision. Ann Thorac Surg 53:780-785 (discussion 785-786)
McCormack PM, Burt ME, Bains MS, Martini N, Rusch VW, Ginsberg RJ (1992) Lung resection for colorectal metastases. 10-year results. Arch Surg 127:1403-1406

Mitry E, Guiu B, Cosconea S, Jooste V, Faivre J, Bouvier AM (2010) Epidemiology, management and prognosis of colorectal cancer with lung metastases: a 30-year population-based study. Gut 59:1383-1388

Muñoz Llarena A, Revilla SC, Laborda AGN, Ferrer JP, Galíndez RB, Vivanco GL (2007) Prognostic factors associated with resectable pulmonary metastases from colorectal cancer. Arch Bronconeumol 43:309-316

Nakajima J, Iida T, Okumura S, Horio H, Asamura H, Ozeki Y, Ikeda N, Matsuguma H, Chida M, Otsuka H, Kawamura M, Metastatic Lung Tumor Study Group of J (2017) Recent improvement of survival prognosis after pulmonary metastasectomy and advanced chemotherapy for patients with colorectal cancer. Eur J Cardiothorac Surg 51:869-873

Nordlinger B, Sorbye H, Glimelius B, Poston GJ, Schlag PM, Rougier P, Bechstein WO, Primrose JN, Walpole ET, Finch-Jones M, Jaeck D, Mirza D, Parks RW, Collette L, Praet M, Bethe U, Van Cutsem E, Scheithauer W, Gruenberger T, Group EG-ITC, Cancer Research UK, Arbeitsgruppe Lebermetastasen und-tumoren in der Chirurgischen Arbeitsgemeinschaft O, Australasian Gastro-Intestinal Trials G, Federation Francophone de Cancerologie D (2008) Perioperative chemotherapy with FOLFOX4 and surgery versus surgery alone for resectable liver metastases from colorectal cancer (EORTC Intergroup trial 40983): a randomised controlled trial. Lancet 371:1007-1016

Okumura T, Boku N, Hishida T, Ohde Y, Sakao Y, Yoshiya K, Higashiyama M, Hyodo I, Mori K, Kondo H (2017) Surgical outcome and prognostic stratification for pulmonary metastasis from colorectal cancer. Ann Thorac Surg 104:979-987

Park HS, Jung M, Shin SJ, Heo SJ, Kim CG, Lee MG, Beom SH, Lee CY, Lee JG, Kim DJ, Ahn JB (2016) Benefit of adjuvant chemotherapy after curative resection of lung metastasis in colorectal cancer. Ann Surg Oncol 23:928-935

Park S, Kang BW, Lee SJ, Yoon S, Chae YS, Kim JG, Lee KH, Koh SA, Song HS, Park KU, Kim JY, Heo MH, Ryoo HM, Cho YY, Jo J, Lee JL, Lee SA (2017) Clinical significance of systemic chemotherapy after curative resection of metachronous pulmonary metastases from colorectal cancer. Cancer Chemother Pharmacol 80:187-193

Pfannschmidt J, Dienemann H, Hoffmann H (2007) Surgical resection of pulmonary metastases from colorectal cancer: a systematic review of published series. Ann Thorac Surg 84:324-338

Pfannschmidt J, Hoffmann H, Dienemann H (2010) Reported outcome factors for pulmonary resection in metastatic colorectal cancer. $\mathrm{J}$ Thorac Oncol 5:S172-178

Salah S, Watanabe K, Welter S, Park JS, Park JW, Zabaleta J, Ardissone F, Kim J, Riquet M, Nojiri K, Gisabella M, Kim SY, Tanaka K, Al-Haj Ali B (2012) Colorectal cancer pulmonary oligometastases: pooled analysis and construction of a clinical lung metastasectomy prognostic model. Ann Oncol 23:2649-2655

Salah S, Ardissone F, Gonzalez M, Gervaz P, Riquet M, Watanabe K, Zabaleta J, Al-Rimawi D, Toubasi S, Massad E, Lisi E, Hamed OH (2015) Pulmonary metastasectomy in colorectal cancer patients with previously resected liver metastasis: pooled analysis. Ann Surg Oncol 22:1844-1850

Saltz LB, Douillard JY, Pirotta N, Alakl M, Gruia G, Awad L, Elfring GL, Locker PK, Miller LL (2001) Irinotecan plus fluorouracil/ leucovorin for metastatic colorectal cancer: a new survival standard. Oncologist 6:81-91

Shiomi K, Naito M, Sato T, Nakamura T, Nakashima H, Naito M, Mikubo M, Matsui Y, Watanabe M, Satoh Y (2017) Effect of adjuvant chemotherapy after pulmonary metastasectomy on the prognosis of colorectal cancer. Ann Med Surg (Lond) 20:19-25 
Torre LA, Bray F, Siegel RL, Ferlay J, Lortet-Tieulent J, Jemal A (2015) Global cancer statistics, 2012. CA Cancer J Clin 65:87-108

Van Cutsem E, Cervantes A, Adam R, Sobrero A, Van Krieken JH, Aderka D, Aranda Aguilar E, Bardelli A, Benson A, Bodoky G, Ciardiello F, D'Hoore A, Diaz-Rubio E, Douillard JY, Ducreux M, Falcone A, Grothey A, Gruenberger T, Haustermans K, Heinemann V, Hoff P, Kohne CH, Labianca R, Laurent-Puig P, Ma B, Maughan T, Muro K, Normanno N, Osterlund P, Oyen WJ, Papamichael D, Pentheroudakis G, Pfeiffer P, Price TJ, Punt C, Ricke J, Roth A, Salazar R, Scheithauer W, Schmoll HJ, Tabernero J, Taieb J, Tejpar S, Wasan H, Yoshino T, Zaanan A, Arnold D (2016) ESMO consensus guidelines for the management of patients with metastatic colorectal cancer. Ann Oncol 27:1386-1422

Welter S, Jacobs J, Krbek T, Krebs B, Stamatis G (2007) Long-term survival after repeated resection of pulmonary metastases from colorectal cancer. Ann Thorac Surg 84:203-210
Yaeger R, Cercek A, Chou JF, Sylvester BE, Kemeny NE, Hechtman JF, Ladanyi M, Rosen N, Weiser MR, Capanu M, Solit DB, D'Angelica MI, Vakiani E, Saltz LB (2014) BRAF mutation predicts for poor outcomes after metastasectomy in patients with metastatic colorectal cancer. Cancer 120:2316-2324

Zampino MG, Maisonneuve P, Ravenda PS, Magni E, Casiraghi M, Solli P, Petrella F, Gasparri R, Galetta D, Borri A, Donghi S, Veronesi G, Spaggiari L (2014) Lung metastases from colorectal cancer: analysis of prognostic factors in a single institution study. Ann Thorac Surg 98:1238-1245

Publisher's Note Springer Nature remains neutral with regard to jurisdictional claims in published maps and institutional affiliations. 